\title{
Repeated Nicotine Exposure Enhances Reward-Related Learning in the Rat
}

\author{
Peter Olausson', J David Jentsch ${ }^{1,2}$ and Jane R Taylor*,1 \\ 'Department of Psychiatry, Laboratory of Molecular Psychiatry, Yale University, New Haven, CT, USA
}

\begin{abstract}
Repeated exposure to addictive drugs causes neuroadaptive changes in cortico-limbic-striatal circuits that may underlie alterations in incentive-motivational processes and reward-related learning. Such drug-induced alterations may be relevant to drug addiction because enhanced incentive motivation and increased control over behavior by drug-associated stimuli may contribute to aspects of compulsive drug-seeking and drug-taking behaviors. This study investigated the consequences of repeated nicotine treatment on the acquisition and performance of Pavlovian discriminative approach behavior, a measure of reward-related learning, in male rats. Water-restricted rats were trained to associate a compound conditioned stimulus (tone+light) with the availability of water (the unconditioned stimulus) in I5 consecutive daily sessions. In separate experiments, rats were repeatedly treated with nicotine $(0.35 \mathrm{mg} / \mathrm{kg}$, s.c.) either (I) prior to the onset of training, (2) after each daily training session was completed (ie postsession injections), or (3) received nicotine both before the onset of training as well as after each daily training session. In this study, all nicotine treatment schedules increased Pavlovian discriminative approach behavior and, thus, prior repeated exposure to nicotine, repeated postsession nicotine injections, or both, facilitated rewardrelated learning.

Neuropsychopharmacology (2003) 28, 1264-127I, advance online publication, 9 April 2003; doi:I0.1038/sj.npp. I 300173
\end{abstract}

Keywords: addiction; motivation; learning; reward; nicotine; rat

\section{INTRODUCTION}

Repeated exposure to drugs of abuse produces long-lasting behavioral alterations and neural adaptations in cortical, limbic, and striatal brain regions (Robinson and Berridge, 1993, 2000; O'Brien et al, 1998; Jentsch and Taylor, 1999; Berke and Hyman, 2000; Hyman and Malenka, 2001; Vanderschuren and Kalivas, 2000; Nestler, 2001). These cellular and physiological changes have been argued to occur within neuronal systems involved in incentive motivation, behavioral control, and learning and memory processes. We have hypothesized that drug-induced changes in cortico-limbic-striatal brain circuits result in enhanced incentive-motivational salience of drugs and drug-associated stimuli as well as deficits in inhibitory control processes (Jentsch and Taylor, 1999, 2000; Olausson et al, 2000, 2002; Taylor and Jentsch, 2001). These druginduced alterations could lead to neurocognitive deficits (Rogers and Robbins, 2001) and, together, such motivational-cognitive alterations may contribute to the expres-

*Correspondence: Dr JR Taylor, Department of Psychiatry, Laboratory of Molecular Psychiatry, Yale University, A. Ribicoff Research Facilities, CMHC, 34 Park St., New Haven, CT 06508, USA, Tel: + I 203974 7727, Fax: + I 203974 7724, E-mail: jane.taylor@yale.edu

2Current address: Department of Psychology, UCLA, 1285 Franz Hall, Los Angeles, CA 90095, USA

Received 26 September 2002; revised I 5 January 2003; accepted 20 January 2003

Online publication: 24 January 2003 at http://www.acnp.org/citations/ Npp0 12403470 sion of addictive behaviors and compulsive drug-seeking and -taking behaviors.

The compulsive use of drugs observed in smokers and drug abusers is commonly associated with stimulusdependent drug-seeking and drug-taking behaviors (cf Tiffany and Carter, 1998; Caggiula et al, 2001). Indeed, these behaviors can be influenced by reward-associated conditioned stimuli (CS), or 'cues', that gain the ability to modulate incentive-motivational processes through their acquired conditioned reinforcing qualities. In humans, drug-associated CS precipitate drug craving (O'Brien $e$ t al, 1998; Childress et al, 1999) and produce region-specific activation of cortico-limbic-striatal brain regions (Grant et al, 1996; Childress et al, 1999; Volkow and Fowler, 2000; Due et al, 2002). In rats, reward-associated stimuli support nicotine self-administration (Caggiula et al, 2001), produce reinstatement of drug-seeking behavior (Grimm et al, 2001; See, 2002), and elicit reward-motivated behaviors, including Pavlovian discriminative approach behavior (Everitt et al, 1999; Cardinal et al, 2002). The acquisition of such Pavlovian discriminative approach behavior may be a direct measure of processes involved in the ability of rewardassociated CS to control behavior. In this task, animals learn to associate a CS with delivery of an appetitive reinforcer. On consecutive days, animals are trained to approach the magazine (ie where the reinforcement is delivered) only during presentation of the CS, or the US. Thus, the subjects learn to discriminate CS and US periods from other times and come to selectively approach the magazine during presentation of the CS or the US. This type of stimulus- 
reward learning may be one functionally relevant mechanism by which drug-associated CS, or cues, support addictive behaviors (Everitt et al, 2001).

Psychostimulant drugs can facilitate the acquisition of Pavlovian approach behavior either after single dose treatment (Hitchcott et al, 1997) or repeated pre-exposure (Harmer and Phillips, 1998; Taylor and Jentsch, 2001). Nicotine can also facilitate learning and cognitive processes in several different animal models (Rezvani and Levin, 2001), and nicotine has been argued to be particularly effective in establishing or enhancing the incentive-motivational properties of reward-associated conditioned cues (Balfour et al, 2000; Caggiula et al, 2001). External and sensory conditioned cues may play a critical role in tobacco addiction (Balfour et al, 2000; Caggiula et al, 2001) and, more specifically, in the maintenance of nicotine-taking behavior (Brauer et al, 2001). Consequently, stimuli associated with smoking or nicotine produce craving and support smoking behavior in humans (Mucha et al, 1999; Dols et al, 2000). Similarly, preclinical experiments have also indicated an important role of nicotine-associated CS in nicotine-seeking and nicotine-taking behavior, and this relation has been demonstrated in the nicotine selfadministration paradigm where such stimuli support instrumental behavior even in the absence of nicotine (Caggiula et al, 2001). Together, these observations implicate nicotine-induced alterations in cue-elicited behaviors in incentive-motivational processes that are relevant to clinical aspects of smoking and drug addiction. However, no preclinical experiments have directly tested the hypothesis that repeated nicotine exposures facilitate rewardrelated learning relevant to addiction.

The present study examined the effects of repeated nicotine administration on reward-related learning measured by Pavlovian discriminative approach behavior. Specifically, we investigated whether repeated daily nicotine treatment for 15 days administered prior to the onset of behavioral testing would enhance Pavlovian discriminative approach behavior. In addition, nicotine's effect on Pavlovian discriminative approach behavior was further examined by giving animals repeated nicotine injections administered $5 \mathrm{~min}$ after the completion of each of 15 daily training sessions (ie 'postsession' treatment). This treatment strategy can be used to dissociate the acute effects of pharmacological manipulations on learning and memory processes from effects of task performance and competing behaviors (McGaugh, 1966). We further evaluated the potentially synergistic effects of a combination of repeated nicotine pretreatment prior to learning and daily postsession nicotine injections. Together, these studies are critical in determining how repeated nicotine administration affects processes implicated in the control of behavior by rewardrelated learning that may have relevance to nicotine addiction.

\section{MATERIALS AND METHODS}

\section{Animals}

Male Sprague-Dawley rats $(n=76)$ weighing $250-300 \mathrm{~g}$ at the start of the experiments, were supplied by Charles River (Portage, ME, USA). The rats were housed in pairs under constant cage temperature $\left(20-21^{\circ} \mathrm{C}\right)$, humidity $(40-50 \%)$, and a controlled $12 / 12 \mathrm{~h}$ light-dark cycle (light on at $7 \mathrm{am}$ and off at $7 \mathrm{pm}$ ), and were initially allowed 7 days to adjust to the housing facilities. The rats had free access to food at all times. Water was available ad libitum until 3 days prior to the first day of training, and immediately after the 15-day training phase was completed. During the 3 days prior to the start of training, animals were restricted to $30 \mathrm{~min}$ access to water per day. During the testing period, water was intermittently available in the operant chambers according to the behavioral task protocol (see below) as well as in the home cage for $30 \mathrm{~min}$, beginning $30 \mathrm{~min}$ after the daily testing session. The experiments in the present study were approved by the Yale University Animal Care and Use Committee (YACUC) and followed the NIH Guide for the Care and Use of Laboratory Animals.

\section{Drugs}

(-)-Nicotine ditartrate (Sigma, USA) was dissolved in a sterile $0.9 \%$ sodium chloride solution, and the $\mathrm{pH}$ of the nicotine solution was neutralized with sodium bicarbonate. Nicotine was injected subcutaneously (s.c.) at $2 \mathrm{ml} / \mathrm{kg}$. The dose of nicotine is expressed as the weight of the free base of nicotine.

\section{Experimental Techniques}

Locomotor activity. Locomotor activity was measured using automated activity meters (Digiscan animal activity monitor, Omnitech Electronics, USA). The activity meters were equipped with two parallel rows of infrared photosensors, each row consisting of 16 sensors placed $2.5 \mathrm{~cm}$ apart. The activity meters were controlled by and data from the activity meters collected by a PC using the Micropro software (Omnitech Electronics, USA).

Rats were placed in transparent plastic boxes that were fitted into the activity meters. The rats were initially allowed to habituate to the locomotor activity recording equipment for $30 \mathrm{~min}$, after which they were taken out, injected with nicotine or vehicle, and placed back into the boxes. Locomotor activity was then recorded for $60 \mathrm{~min}$ starting $5 \mathrm{~min}$ after drug injection. All experiments were performed between $8 \mathrm{am}$ and $6 \mathrm{pm}$.

\section{Pavlovian discriminative approach behavior}

Schedule using paired presentation of the CS and the US: Standard aluminum operant chambers $\left(30 \times 20 \times 25 \mathrm{~cm}^{3}\right)$ with grid floors (Med Associates Inc., USA) were used to study the acquisition of Pavlovian discriminative approach behavior. Each operant chamber was housed in a sound attenuating outer box equipped with a white noise generator and a fan to reduce external noise. A liquid dipper $(0.06 \mathrm{ml})$ delivered water as the reinforcer into the magazine. Head entries were detected by a photocell mounted within the magazine, above the reinforcer receptacle. Above the magazine was a $2.5 \mathrm{~W}, 24 \mathrm{~V}$ light. The operant chamber was illuminated by house light mounted on the back wall. A Sonalert tone $(10 \mathrm{kHz})$ generator was mounted above the magazine. A PC with interface and the MedPC software (Med Associates Inc., USA) controlled the boxes. 
On the first day, 5-s access to $0.06 \mathrm{ml}$ water (the unconditioned stimulus (US)) was available in the dipper on a fixed time 15-s (FT-15) schedule; the session ended after the delivery of 100 reinforcers. Beginning on the second day, the subjects received 30 pairings of a 5-s compound conditioned stimulus (CS; light + tone) followed immediately by 5 -s access to $0.06 \mathrm{ml}$ of water; the CS + US pairings were delivered on a random time 30-s (RT-30) schedule. Head entries during the RT-30 interval resulted in a 3-s delay during which time no reinforcement was given, and the RT-30 schedule was restarted. Training on this schedule results in a discriminated pattern of approach of the magazine during $\mathrm{CS}+\mathrm{US}$, but not during inter-CS + US, periods.

Schedule using nonpaired presentation of the CS and the US: On the first day, 5-s access to $0.06 \mathrm{ml}$ water (ie the US) was available in the receptacle on a FT-15 schedule; the session ended after the delivery of 100 reinforcers. Beginning on the second day, the subjects randomly received 30 presentations of each of the 5-s CS and 5-s access to $0.06 \mathrm{ml}$ of water. Two independent RT-30 schedules separately controlled delivery of the CS or US; however, the following additional conditions applied: (1) the presentations of the CS and the US never overlapped and were not presented within 5-s of each other and (2) head entries during either of the RT-30 intervals resulted in a 3-s delay during which time no CS or reinforcement was presented, and the RT-30 schedules were restarted.

\section{Experimental Design}

Experiment using paired presentation of the CS and the US. Animals $(n=56)$ were randomly divided into two experimental groups. One group $(n=28)$ received daily injections (15 consecutive days) with nicotine $(0.35 \mathrm{mg} / \mathrm{kg}$ s.c.) and the control group $(n=28)$ received the equal volume of a sterile $0.9 \%$ sodium chloride solution. Locomotor activity was recorded on treatment days 1 and 15. These animals were then divided into four balanced groups $(n=14)$, two nicotine-treated and two vehicletreated. After 3 days of withdrawal, all rats were subjected to the Pavlovian discriminatory approach behavior task described above for 15 consecutive days. During the behavioral testing phase, the animals received either daily injections of nicotine $(0.35 \mathrm{mg} / \mathrm{kg}$ s.c. $)$ and/or $0.9 \%$ sodium chloride $5 \mathrm{~min}$ after each training session had been completed, yielding the following four experimental groups (pretreatment/postsession treatment): vehicle/vehicle (Veh/ Veh), vehicle/nicotine (Veh/Nic), nicotine/vehicle (Nic/ $\mathrm{Veh}$ ), and nicotine/nicotine (Nic/Nic).

Experiment using nonpaired presentation of the CS and the US. Animals $(n=20)$ were randomly divided into two experimental groups. One group $(n=10)$ received daily injections (15 consecutive days) with nicotine $(0.35 \mathrm{mg} / \mathrm{kg}$ s.c.) and the control group $(n=10)$ received an equal volume of $0.9 \% \mathrm{NaCl}$. After 3 days of withdrawal, all rats were subjected to the task in which the tone + light CS never predicted US availability, as described above, for 15 consecutive days.

\section{Statistics}

The data from the present experiments were evaluated using a one or two-way analysis of variance (ANOVA), for repeated measures where appropriate. In the analysis of locomotor activity, treatment (nicotine or vehicle) was the between-subject factor and treatment day (ie testing on day 1 or 15 of treatment) was used as the within-subject factor. In the ANOVA analyses of reward-related learning, pretreatment (ie treatment prior to onset of behavioral testing; nicotine or vehicle), postsession treatment (ie treatment administered after completion of each daily training session; nicotine or vehicle were there between subject factors. Within-subject measure was training days. Post hoc comparisons were performed using Fischer's PLSD, paired $t$-test, Bonferroni-Dunn or Tukey-Kramer's post hoc tests where appropriate. A probability value $(p)$ equal to or less than 0.05 was considered statistically significant.

\section{RESULTS}

\section{Locomotor Activity Studies}

In the locomotor activity experiments, there were two experimental groups, one nicotine-treated and one salinetreated control group. In this experiment, there were statistically significant main effects of treatment $\left(\mathrm{F}_{1,54}=44.662 ; p<0.001\right)$ and treatment days (the repeated measure; $\left.F_{1,54}=19.487 ; p<0.001\right)$ as well as a significant treatment $\times$ treatment day interaction $\left(\mathrm{F}_{1,54}=32.704\right.$; $p<0.001$; Figure 1). The post hoc analysis, made with Fisher's PLSD test on the data obtained on day 1, demonstrated that acute treatment with nicotine $(0.35 \mathrm{mg} /$ kg s.c.) stimulated locomotor activity $(p<0.001)$. A paired $t$ test revealed that daily treatment with nicotine enhanced the behavioral response to a subsequent injection of nicotine $(p<0.001)$. Daily vehicle injections for 15 days did not alter the baseline locomotor activity. Moreover, there were no treatment differences in spontaneous

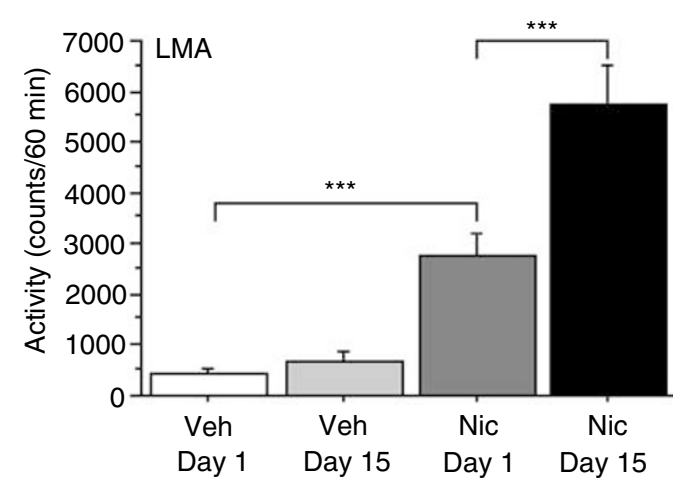

Figure I Animals received daily injections with nicotine $(0.35 \mathrm{mg} / \mathrm{kg}$, s.c.; $n=28)$ or vehicle $(n=28)$ for 15 consecutive days, and the effect of vehicle or nicotine on locomotor activity was evaluated on treatment days I and 15. Acute administration of nicotine $(0.35 \mathrm{mg} / \mathrm{kg}$, s.c.; $-5 \mathrm{~min})$ increased locomotor activity, and this effect was enhanced on day 15 after repeated nicotine treatment. Repeated treatment with vehicle had no significant effect. Data are presented as the mean total locomotor activity counts/60 $\min ( \pm \mathrm{SEM}$ ). **** $p \leqslant 0.00$ I (ANOVA followed by the paired $t$ test). 
locomotor activity during the habituation phase on day 15 (data not shown).

\section{Reward-Related Learning}

Repeated treatment with nicotine did not alter magazine approach during the initial magazine training session (data not shown). Thus, the repeated drug treatment does not appear to affect primary motivation for water or ability to obtain water from the dipper. We first performed an overall ANOVA on approach during the CS period to probe the main effects of pretraining treatment ('pretreatment') and postsession treatment across days of training (the repeated measure). There were statistically significant main effects of training days (indicating that CS-evoked magazine approach progressively increased as a function of training; $\left.\mathrm{F}_{4,728}=91.393 ; p<0.0001\right)$, pretreatment $\left(\mathrm{F}_{1,52}=4.042 ;\right.$ $p<0.05)$ as well as postsession treatment $\left(\mathrm{F}_{1,52}=4.117\right.$; $p<0.05)$ on magazine entries made during CS presentation (Figure 2a). There were no differences on measures of magazine approach on training day 1 according to Bonferroni-Dunn post hoc test, indicating that repeated nicotine treatment did not alter the initial level of performance on this task. Tukey-Kramer's post hoc analysis revealed that all nicotine treatment schedules (ie Veh/Nic; $\mathrm{Nic} / \mathrm{Veh}$; Nic/Nic) increased CS magazine approach during the behavioral testing phase compared to vehicle-treated control animals.

The Tukey-Kramer test also showed that the CS magazine approach on training day 4 did not significantly differ from that observed on training day 3 . Thus, the acquisition of the Pavlovian discriminative approach behavior appeared to occur within the three initial days of training. When analyzed using a repeated measures ANOVA only over these first 3 days of training, there were significant main effects of treatment $\left(\mathrm{F}_{3,52}=5.908 ; p<0.05\right)$ and training days $\left(F_{2,104}=154.042 ; p<0.001\right)$, as well as a significant treatment $\times$ training day interaction $\left(\mathrm{F}_{6,104}=2.538 ; p<0.05\right.$, Figure 3a). Tukey-Kramer's post hoc analysis revealed differences in all nicotine-treated groups (ie Veh/Nic; Nic/ Veh; Nic/Nic) during the acquisition phase. Together, these results indicate that the nicotine treatment facilitated learning about the stimulus-reward associations.

There was a significant main effect of training days $\left(\mathrm{F}_{4,728}=125.032 ; p<0.0001\right)$ and pretreatment on magazine approach during US presentation $\left(\mathrm{F}_{1,52}=6.213 ; p<0.05\right.$, Figure 2b); repeated treatment with nicotine prior to training thus resulted in an increased approach to the magazine during US presentation. The Tukey-Kramer post hoc test confirmed that this significant difference was attributed to enhanced US approach in animals receiving repeated nicotine treatment before the onset of behavioral testing in combination with postsession nicotine injections (Figure 2b). Nonspecific approach to the magazine during the inter-CS + US period was not affected by nicotine pretreatment $\left(\mathrm{F}_{1,52}=0.4\right.$; NS) or by postsession treatment $\left(\mathrm{F}_{1,52}=0.301\right.$; NS, Figure $\left.2 \mathrm{c}\right)$.

In the experiment in which the CS and US were never paired (see Experiment using nonpaired presentation of the CS and the US), prior repeated nicotine treatment did not alter magazine approach during $\mathrm{CS} \quad\left(\mathrm{F}_{1,18}=2.722\right.$; NS, Figure $4 \mathrm{a})$ or US $\left(\mathrm{F}_{1,18}=0.231\right.$; NS, Figure $\left.4 \mathrm{~b}\right)$ periods. On
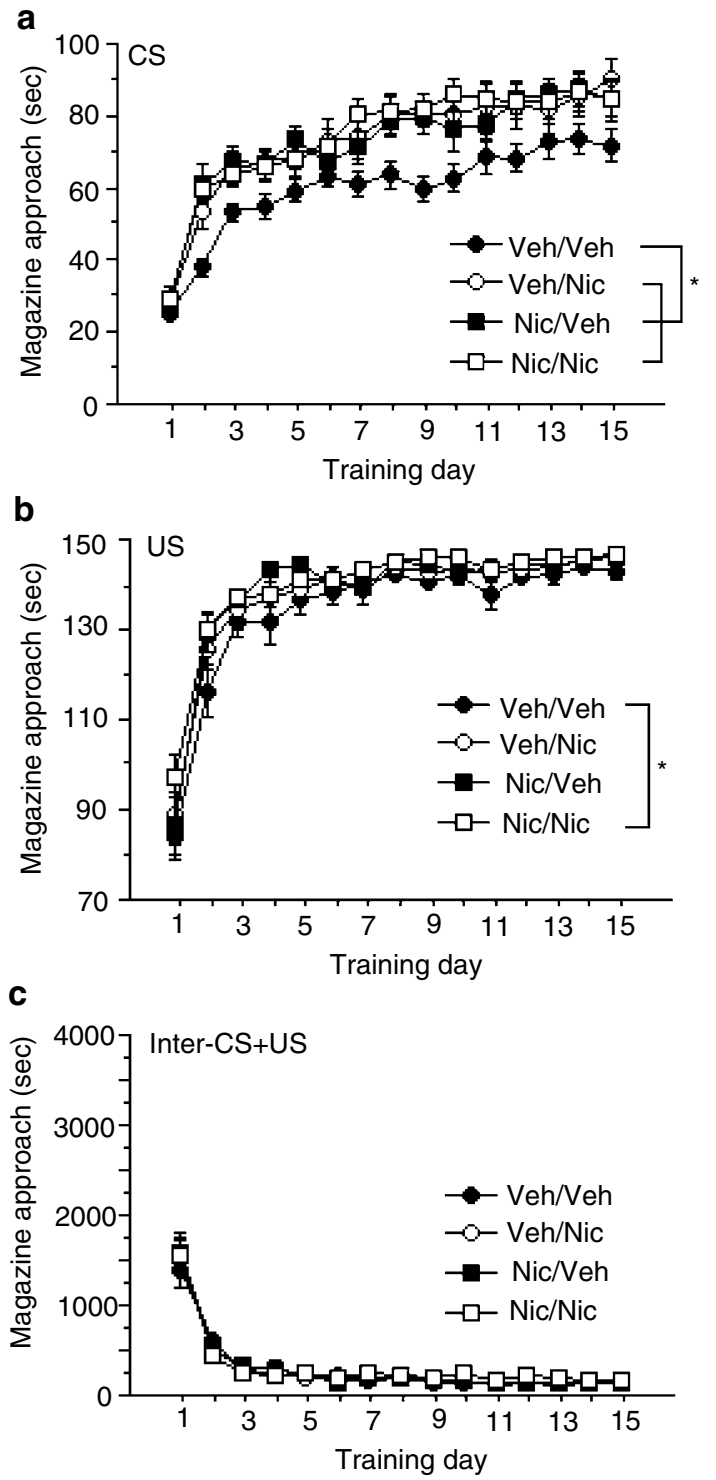

Figure 2 The effect of repeated nicotine $(0.35 \mathrm{mg} / \mathrm{kg}$, s.c.) treatment on magazine head entries during CS, US, and inter-CS + US periods in the Pavlovian discriminative approach behavior task. All animals received daily injections with Nic or Veh 15 days prior to the onset of training on Pavlovian discriminative approach behavior as well as after the completion of each of 15 daily training sessions, resulting in the following experimental groups (prior repeated treatment/postsession treatment: Veh/Veh, Veh/ $\mathrm{Nic}, \mathrm{Nic} / \mathrm{Veh}$, and $\mathrm{Nic} / \mathrm{Nic} ; n=14$ all groups). Repeated nicotine administration according to either of these treatment paradigms increased CS magazine approach, and treatment with nicotine prior to the onset of behavioral testing increased the magazine entries during presentation of the US. Data are presented as the mean total magazine head entries in seconds ( \pm SEM) for daily test sessions. *Indicates a statistically significant group difference (ANOVA followed by Tukey-Kramer's post hoc test).

the other hand, prior repeated nicotine treatment increased magazine entries during inter-CS + US periods $\left(\mathrm{F}_{1,18}=9.427\right.$; $p<0.001$, Figure $4 c$ ).

\section{DISCUSSION}

The present study investigated the effects of repeated nicotine treatment on Pavlovian discriminative approach 

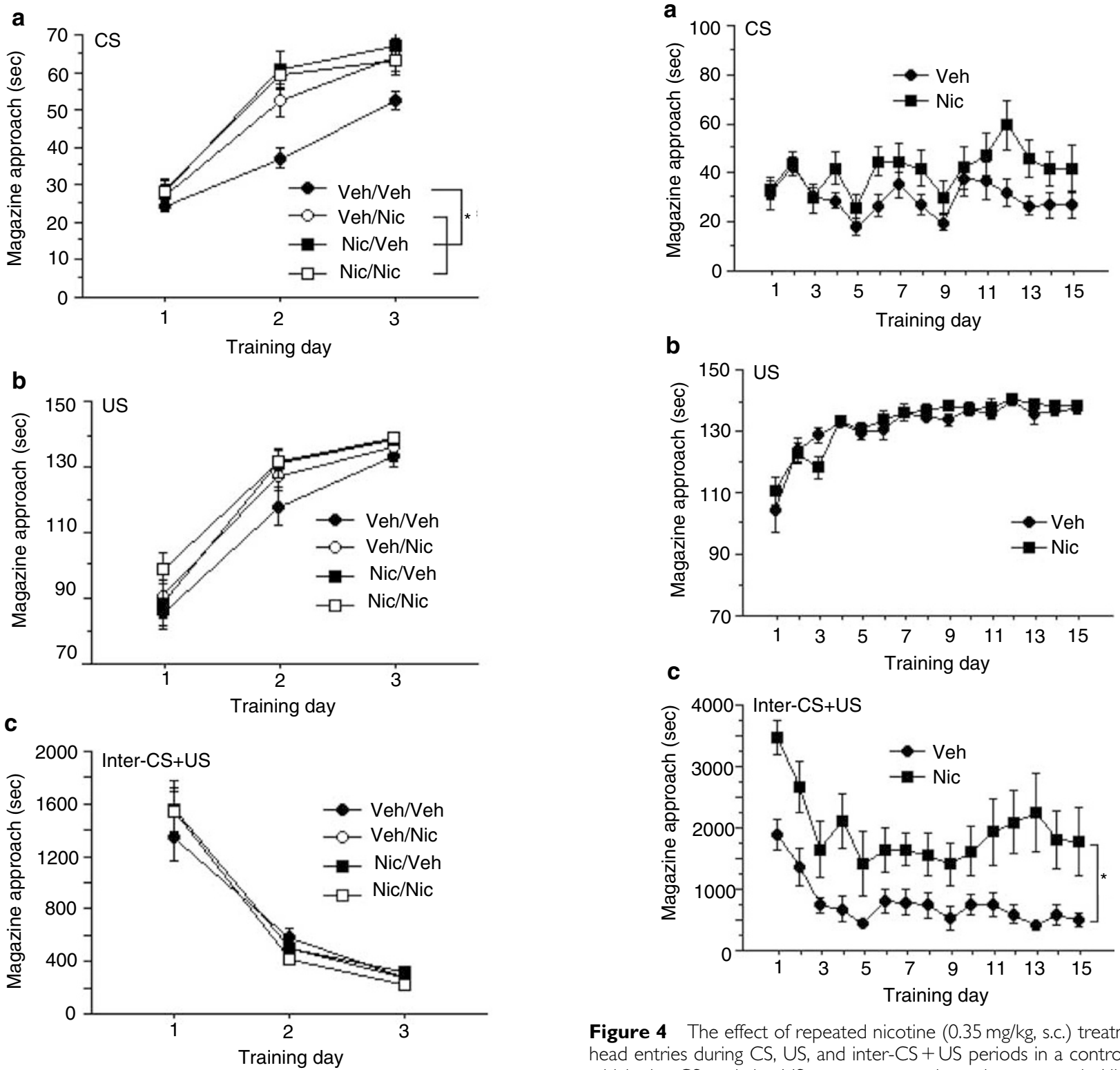

Figure 4 The effect of repeated nicotine $(0.35 \mathrm{mg} / \mathrm{kg}$, s.c.) treatment on head entries during CS, US, and inter-CS + US periods in a control task in which the CS and the US are never contingently presented. All animals received daily nicotine $(n=10)$ or vehicle $(n=10)$ injections for 15 days prior to the onset of training. Repeated nicotine administration had no effect of magazine entries during CS or US presentation, but increased magazine head entries during inter-CS + US periods. Data are presented as the mean total magazine head entries in seconds ( \pm SEM) for daily test sessions. * Indicates a statistically significant group difference (ANOVA followed by Tukey-Kramer's post hoc test). following experimental groups (prior repeated treatment/postsession treatment: Veh/Veh, Veh/Nic, Nic/Neh, and Nic/Nic; $n=14$ all groups). Repeated nicotine administration according to either of these treatment paradigms increased CS magazine approach, and treatment with nicotine prior to the onset of behavioral testing increased the magazine entries during presentation of the US. Data are presented as the mean total magazine head entries in seconds $( \pm$ SEM) for daily test sessions. *Indicates a statistically significant group difference (ANOVA followed by TukeyKramer's post hoc test).

behavior in rats. These experiments demonstrate that repeated treatment with nicotine for 15 days prior to reward-related learning, nicotine injections given after each of 15 daily training sessions, or a combination of both prior and postsession treatment, increased head entries into the magazine during presentation of a CS that predicted US

availability. These findings confirm previous observations made after prior repeated administration of other psychostimulants (Harmer and Phillips, 1998; Taylor and Jentsch, 2001), and support the hypothesis that repeated nicotine exposures produce long-lasting and functionally significant alterations in neurobiological processes subserving incentive motivation and reward-related learning that are relevant to addiction. These studies also extend previous findings by suggesting that repeated prior drug exposure and repeated postsession injections may produce similar behavioral effects on incentive-motivational processes and reward-related learning. 
A control study confirmed that the nicotine-induced enhancement of reward-related learning was specifically because of the predictive relation between the CS and the US. In this experiment, the CS and US were never explicitly paired, and magazine entries during presentation of the CS or the US were unaffected by the prior repeated nicotine treatment. Interestingly, the level of US magazine entries observed in this experiment was not significantly different from the US entries observed when the CS and the US were paired. All animals thus seem to be able to discriminate periods of US availability using subtle cues or occasion setters (eg the sound of the dipper moving). Notably, prior repeated nicotine treatment produced increased responding at other times than when the CS or the US was presented. Since premature magazine entries were punished by a delay of the presentations of both the CS and the US, the increased inappropriate approach behavior could reflect a nicotine-induced impairment in inhibitory control in line with our previous observations (Olausson et al, 1999, $2001 \mathrm{a}-\mathrm{c})$. It is interesting that the increased 'inappropriate' approach was only observed when the CS and the US were specifically unpaired. However, given the enhanced rewardrelated learning observed here following repeated nicotine exposure, one possibility is that the inhibitory control deficit is overshadowed by increased learning when the CS and the US is paired, but that the deficit in behavioral control is expressed when the animal is unable to guide behavior through learning of a new Pavlovian association between the CS and the US.

\section{Specific Requirements for Repeated Nicotine Treatment: Potential Mechanisms?}

Prior repeated nicotine injections alter the effects of nicotine on a number of neuronal processes and behavioral measures. Most studies have reported that repeated nicotine exposure produces sensitization to these behavioral, neurochemical and molecular effects, including augmented nicotine-induced locomotor activity (Clarke and Kumar, 1983; Clarke et al, 1988), elevated nicotine-induced dopamine efflux in the nucleus accumbens (N Acc; Balfour et al, 2000), and increased expression of molecular targets including some immediate-early genes (Nisell et al, 1997; Pich et al, 1997; Mathieu-Kia et al, 1998; Ferrari et al, 2001). Repeated or chronic nicotine treatment has also been found to increase self-administration of other drugs, including alcohol (Blomqvist et al, 1996) and cocaine (Horger et al, 1992). Moreover, nicotine typically facilitates learning and cognitive processes (Rezvani and Levin, 2001). To investigate the role of sensitization in the effects of nicotine on reward-reward learning in the Pavlovian discriminative approach behavior paradigm, we treated one experimental group with daily nicotine injections both prior to the onset of training (15 days) as well as giving postsession treatment during the 15 day behavioral testing phase. Combined treatment did not further augment the nicotine-induced enhancement of CS magazine approach compared to rats receiving repeated nicotine treatment prior to the onset of learning or postsession nicotine injections alone, indicating that prior repeated treatment and postsession nicotine injections did not produce synergistic effects in this behavioral paradigm. However, it is also possible that ceiling effects prevented any additional enhancement of Pavlovian discriminative approach behavior in the group receiving both prior and postsession nicotine treatments.

The acquisition of Pavlovian discriminative approach behavior is dependent on processes mediated by corticolimbic-striatal brain circuits. For example, neurotoxic lesions of the $\mathrm{N} \mathrm{Acc}$ core and the central nucleus of the amygdala disrupt acquisition of Pavlovian approach behavior (for a review, see Everitt et al, 1999; Cardinal et al, 2002). These brain regions receive afferent input from the mesocorticolimbic dopamine neurons, and repeated nicotine treatment produce long-lasting neuroadaptations in this dopamine pathway, as well as in other forebrain and cortical areas (Nisell et al, 1996; Balfour et al, 2000; Di Chiara, 2000; Olausson et al, 2001a, b; Pandey et al, 2001). Moreover, dopamine neurotransmission in both the $\mathrm{N}$ Acc and the amygdala has been implicated in Pavlovian approach behavior (Hitchcott and Phillips, 1998; Parkinson et al, 1999; Everitt et al, 1999; Phillips et al, 2002; Cardinal et $a l, 2002)$, as well as in the effects of repeated psychostimulant treatment on Pavlovian discriminative approach behavior (Jentsch and Taylor, 1999; Harmer and Phillips, 1999). It is also likely that repeated nicotine injections induce alterations in dopamine-regulated intracellular signaling via the D1/cyclic-Adenosine-Mono-Phosphate (cAMP)/Protein Kinase A (PKA) signaling pathway within these brain circuits, effects that may contribute to the increased approach of the magazine during CS presentation observed in nicotine-treated animals.

The cAMP/PKA signaling pathway, and its downstream molecular targets, influence gene transcription critical for emotional learning (Silva et al, 1998; Schafe et al, 2001). Indeed, using the present Pavlovian discriminative approach behavior task we have found that direct activation of cAMP/PKA signaling in the amygdala mimics the behavioral effect found in these experiments, as well as the consequences of repeated cocaine administration on Pavlovian approach behavior (Taylor and Jentsch, 2001; Jentsch et al, 2002). Given that withdrawal from chronic nicotine treatment upregulates cAMP signaling in the amygdala (Tzavara et al, 2002), it seems possible that the enhancement of Pavlovian approach behavior after prior repeated nicotine may occur because of alterations in the dopamine-regulated cAMP/PKA signaling pathway. Since postsession nicotine treatment produced the same results on Pavlovian approach behavior, this raises the possibility that the consequences of postsession or prior repeated nicotine administration produce comparable effects on dopamine-regulated signaling.

\section{Relevance to Stimulus-Control over Behavior}

Recent findings have indicated that nicotine augments the influence of CS on instrumental behavior in the nicotine self-administration paradigm. Caggiula and co-workers (2001) demonstrated that a nicotine-associated CS can support instrumental behavior even in the absence of contingent nicotine availability. This result is consistent with our present observations indicating a powerful control over behavior by reward-associated CS in nicotine-exposed animals. 
The effect of acute and repeated nicotine treatment on processes related to learning and cognitive functions has been extensively examined (Rezvani and Levin, 2001). However, to the best of our knowledge, few, if any, preclinical studies to date have demonstrated long-lasting facilitation of learning processes after withdrawal from repeated or chronic nicotine administration. We have previously found that repeated exposure to psychostimulants and nicotine may produce concurrent changes in the neural processes involved in incentive-motivation/stimulus control over behavior as well as those involved in cognitive functions, especially inhibitory control (Jentsch and Taylor, 1999; Olausson et al, 1999, 2001a-c; Taylor and Jentsch, 2001; Jentsch et al, 2002). In combination, these druginduced effects may result in enhanced control over behavior by reward-associated stimuli and reduced inhibitory modulation of such motivational impulses (Jentsch and Taylor, 1999; Taylor and Jentsch, 2001; Olausson et al, 2002), and such nicotine-induced alterations may subserve the behavioral changes observed here. Together these druginduced alterations are hypothesized to contribute to the compulsive pattern of drug use observed in addiction, but also to cue-induced craving and relapse during short or long periods of drug abstinence. The findings that prior repeated nicotine exposure augments reward-related learning presented here further support the hypothesis that repeated exposure to drugs of abuse, including nicotine, may result in an inability to inhibit reward-elicited behavior indicative of a deficit in inhibitory control functions. Taken together, the present experiments demonstrate that systemic nicotine administration facilitates appetitively motivated stimulus-reward learning in the rat, and suggest that nicotine augments the control over behavior by rewardassociated stimuli. These results may be relevant to nicotine abuse since smoking-related cues possess the ability to elicit craving and support smoking behavior in human smokers, and such cues may be important in relapse after nicotine abstinence (Niaura et al, 1989; Mucha et al, 1998, 1999; Dols et al, 2000).

\section{ACKNOWLEDGEMENTS}

The authors gratefully acknowledge the valuable technical assistance of Ms Valyphone Phantharangsy and Ms Victoria Stewart. The present study was financially supported by a PHS grant (DA 11717) to JRT and a Fredrik \& Inger Thuring's Foundation grant to PO. PO is a recipient of a Swedish Brain Foundation Post-Doctoral Fellowship.

\section{REFERENCES}

Balfour DJ, Wright AE, Benwell ME, Birrell CE (2000). The putative role of extra-synaptic mesolimbic dopamine in the neurobiology of nicotine dependence. Behav Brain Res 113: 73-83.

Berke JD, Hyman SE (2000). Addiction, dopamine, and the molecular mechanisms of memory. Neuron 25: 515-532.

Blomqvist O, Ericson M, Johnson DH, Engel JA, Soderpalm B (1996). Voluntary ethanol intake in the rat: effects of nicotinic acetylcholine receptor blockade or subchronic nicotine treatment. Eur J Pharmacol 314: 257-267.

Brauer LH, Behm FM, Lane JD, Westman EC, Perkins C, Rose JE (2001). Individual differences in smoking reward from denicotinized cigarettes. Nicotine Tob Res 3: 101-109.
Caggiula AR, Donny EC, White AR, Chaudhri N, Booth S, Gharib MA et al (2001). Cue dependency of nicotine self-administration and smoking. Pharmacol Biochem Behav 70: 515-530.

Cardinal RN, Parkinson JA, Hall J, Everitt BJ (2002). Emotion and motivation: the role of the amygdala, ventral striatum, and prefrontal cortex. Neurosci Biobehav Rev 26: 321-352.

Childress AR, Mozley PD, McElgin W, Fitzgerald J, Reivich M, O’Brien CP (1999). Limbic activation during cue-induced cocaine craving. Am J Psychiatry 156: 11-18.

Clarke PB, Fu DS, Jakubovic A, Fibiger HC (1988). Evidence that mesolimbic dopaminergic activation underlies the locomotor stimulant action of nicotine in rats. J Pharmacol Exp Ther 246: 701-708.

Clarke PB, Kumar R (1983). The effects of nicotine on locomotor activity in non-tolerant and tolerant rats. $\mathrm{Br} \mathrm{J}$ Pharmacol 78: 329-337.

Di Chiara G (2000). Role of dopamine in the behavioural actions of nicotine related to addiction. Eur J Pharmacol 393: 295-314.

Dols M, Willems B, van den Hout M, Bittoun R (2000). Smokers can learn to influence their urge to smoke. Addict Behav 25: 103-108.

Due DL, Huettel SA, Hall WG, Rubin DC (2002). Activation in mesolimbic and visuospatial neural circuits elicited by smoking cues: evidence from functional magnetic resonance imaging. $\mathrm{Am}$ J Psychiatry 159: 954-960.

Everitt BJ, Dickinson A, Robbins TW (2001). The neuropsychological basis of addictive behaviour. Brain Res Brain Res Rev 36: 129-138.

Everitt BJ, Parkinson JA, Olmstead MC, Arroyo M, Robledo P, Robbins TW (1999). Associative processes in addiction and reward. The role of amygdala-ventral striatal subsystems. Ann NY Acad Sci 877: 412-438.

Ferrari R, Le Novere N, Picciotto MR, Changeux JP, Zoli M (2001). Acute and long-term changes in the mesolimbic dopamine pathway after systemic or local single nicotine injections. Eur $J$ Neurosci 15: 1810-1818.

Grant S, London ED, Newlin DB, Villemagne VL, Liu X, Contoreggi $C$ et al (1996). Activation of memory circuits during cue-elicited cocaine craving. Proc Natl Acad Sci USA 93: 12040-12045.

Grimm JW, Hope BT, Wise RA, Shaham Y (2001). Neuroadaptation. Incubation of cocaine craving after withdrawal. Nature 412: 141-142.

Harmer CJ, Phillips GD (1998). Enhanced appetitive conditioning following repeated pretreatment with D-amphetamine. Behav Pharmacol 9: 299-308.

Harmer CJ, Phillips GD (1999). Enhanced dopamine efflux in the amygdala by a predictive, but not a non-predictive, stimulus: facilitation by prior repeated D-amphetamine. Neuroscience 90: 119-130.

Hitchcott PK, Harmer CJ, Phillips GD (1997). Enhanced acquisition of discriminative approach following intra-amygdala Damphetamine. Psychopharmacology 132: 237-246.

Hitchcott PK, Phillips GD (1998). Effects of intra-amygdala R(+) 7OH-DPAT on intra-accumbens D-amphetamine-associated learning. I. Pavlovian conditioning. Psychopharmacology 140: 300-309.

Horger BA, Giles MK, Schenk S (1992). Preexposure to amphetamine and nicotine predisposes rats to self-administer a low dose of cocaine. Psychopharmacology 107: 271-276.

Hyman SE, Malenka RC (2001). Addiction and the brain: the neurobiology of compulsion and its persistence. Nat Rev Neurosci 2: 695-703.

Jentsch JD, Olausson P, Nestler EJ, Taylor JR (2002). Stimulation of protein kinase a activity in the rat amygdala enhances rewardrelated learning. Biol Psychiatry 52: 111-118.

Jentsch JD, Taylor JR (1999). Impulsivity resulting from frontostriatal dysfunction in drug abuse: implications for the control of behavior by reward-related stimuli. Psychopharmacology 146: 373-390. 
Jentsch JD, Taylor JR (2000). Impaired inhibition of conditioned responses produced by subchronic administration of phencyclidine to rats. Neuropsychopharmacology 24: 66-74.

Mathieu-Kia AM, Pages C, Besson MJ (1998). Inducibility of c-Fos protein in visuo-motor system and limbic structures after acute and repeated administration of nicotine in the rat. Synapse 29: 343-354.

McGaugh JL (1966). Time-dependent processes in memory storage. Science 153: 1351-1358.

Mucha RF, Geier A, Pauli P (1999). Modulation of craving by cues having differential overlap with pharmacological effect: evidence for cue approach in smokers and social drinkers. Psychopharmacology 147: 306-313.

Mucha RF, Pauli P, Angrilli A (1998). Conditioned responses elicited by experimentally produced cues for smoking. Can J Physiol Pharmacol 76: 259-268.

Nestler EJ (2001). Molecular neurobiology of addiction. Am J Addict 10: 201-217.

Niaura R, Abrams D, Demuth B, Pinto R, Monti P (1989). Responses to smoking-related stimuli and early relapse to smoking. Addict Behav 14: 419-428.

Nisell M, Nomikos GG, Chergui K, Grillner P, Svensson TH (1997). Chronic nicotine enhances basal and nicotine-induced Fos immunoreactivity preferentially in the medial prefrontal cortex of the rat. Neuropsychopharmacology 17: 151-161.

Nisell M, Nomikos GG, Hertel P, Panagis G, Svensson TH (1996). Condition-independent sensitization of locomotor stimulation and mesocortical dopamine release following chronic nicotine treatment in the rat. Synapse 22: 369-381.

O’Brien CP, Childress AR, Ehrman R, Robbins SJ (1998). Conditioning factors in drug abuse: can they explain compulsion? J Psychopharmacol 12: 15-22.

Olausson P, Engel JA, Söderpalm B (1999). Behavioral sensitization to nicotine is associated with behavioral disinhibition: counteraction by citalopram. Psychopharmacology 142: 111-119.

Olausson P, Engel JA, Söderpalm B (2001a). The effect of 5-HT1A and 5-HT2 receptor agonists on the behavioral and neurochemical consequences of repeated nicotine treatment. Eur $J$ Pharmacol 420: 45-54.

Olausson P, Engel JA, Söderpalm B (2002). The involvement of serotonin in nicotine dependence: processes involved in positive and negative regulation of drug intake. Pharmacol Biochem Behav 71: 757-771.

Olausson P, Ericson M, Löf E, Engel JA, Söderpalm B (2001c). Nicotine-induced behavioral disinhibition and ethanol preference correlate after repeated nicotine treatment. Eur J Pharmacol 417: 117-123.

Olausson P, Petersson A, Engel JA, Söderpalm B (2001b). Behavioral and neurochemical consequences of repeated nicotine treatment in the serotonin depleted rat. Psychopharmacology 155: 348-361.

Olausson P, Engel JA, Söderpalm B (2000). Effects of Serotonergic on the behavioral sensitization and disinhibition associated with repeated amphetamine treatment. Pharmacol Biochem Behav 66: 211-220.
Pandey SC, Roy A, Xu T, Mittal N (2001). Effects of protracted nicotine exposure and withdrawal on the expression and phosphorylation of the CREB gene transcription factor in rat brain. J Neurochem 77: 943-952.

Parkinson JA, Olmstead MC, Burns LH, Robbins TW, Everitt BJ (1999). Dissociation in effects of lesions of the nucleus accumbens core and shell on appetitive pavlovian approach behavior and the potentiation of conditioned reinforcement and locomotor activity by D-amphetamine. J Neurosci 19: 2401-2411.

Phillips G, Harmer C, Hitchcott P (2002). Blockade of sensitisation-induced facilitation of appetitive conditioning by postsession intra-amygdala nafadotride. Behav Brain Res 134: 249257.

Pich EM, Pagliusi SR, Tessari M, Talabot-Ayer D, Hooft van Huijsduijnen R, Chiamulera C (1997). Common neural substrates for the addictive properties of nicotine and cocaine. Science 275: 83-86.

Rezvani AH, Levin ED (2001). Cognitive effects of nicotine. Biol Psychiatry 49: 258-267.

Robinson TE, Berridge KC (1993). The neural basis of drug craving: an incentive-sensitization theory of addiction. Brain Res Brain Res Rev 18: 247-291.

Robinson TE, Berridge KC (2000). The psychology and neurobiology of addiction: an incentive-sensitization view. Addiction 95(Suppl 2): S91-S117.

Rogers RD, Robbins TW (2001). Investigating the neurocognitive deficits associated with chronic drug misuse. Curr Opin Neurobiol 11: 250-257.

Schafe GE, Nader K, Blair HT, LeDoux JE (2001). Memory consolidation of Pavlovian fear conditioning: a cellular and molecular perspective. Trends Neurosci 24: 540-546.

See RE (2002). Neural substrates of conditioned-cued relapse to drug-seeking behavior. Pharmacol Biochem Behav 71: 517-529.

Silva AJ, Kogan JH, Frankland PW, Kida S (1998). CREB and memory. Annu Rev Neurosci 21: 127-148.

Taylor JR, Jentsch JD (2001). Repeated intermittent administration of psychomotor stimulant drugs alters the acquisition of Pavlovian approach behavior in rats: differential effects of cocaine, D-amphetamine and 3,4-methylenedioxymethamphetamine ('Ecstasy'). Biol Psychiatry 50: 137-143.

Tiffany ST, Carter BL (1998). Is craving the source of compulsive drug use? J Psychopharmacol 12: 23-30.

Tzavara ET, Monory K, Hanoune J, Nomikos GG (2002). Nicotine withdrawal syndrome: behavioural distress and selective upregulation of the cyclic AMP pathway in the amygdala. Eur $J$ Neurosci 16: 149-153.

Vanderschuren LJ, Kalivas PW (2000). Alterations in dopaminergic and glutamatergic transmission in the induction and expression of behavioral sensitization: a critical review of preclinical studies. Psychopharmacology 151: 99-120.

Volkow ND, Fowler JS (2000). Addiction, a disease of compulsion and drive: involvement of the orbitofrontal cortex. Cereb Cortex 10: $318-325$. 